\title{
WAWASAN GENDER DALAM EKOLOGI ALAM DAN MANUSIA PERSPEKTIF AL QURAN
}

\author{
Nur Arfiyah Febriani \\ Institut Perguruan Tinggi Ilmu Quran (PTIQ) Jakarta \\ Email: royyana12@yahoo.com
}

\begin{abstract}
Quranic perspectives on gender-oriented ecology propose eco humanist theocentric theory. This is based on the Quranic description regarding the interconnection and harmonious interaction between a human and him/her self, a human with another human, a human with the universe, and a human with God, regardless male or female. This study employs tafsir maudu'i (thematic), historical-critical-contextual methods, and qualitative approach. The result shows three representations of gender identity, namely biology paired features, various terms referring to men and women interactions, and the balance of femininity and masculinity within every human being. It indicates the possible equal quality of intellectual, emotion and roles in their social life. In addition, the Quran illustrates that both masculine and feminine characteristics have positive and negative sides. This, in fact, has been a debatable notion in the academic world related to men and women stereotyping, which has influenced their social role divisions. While in natural ecology, gender identity is found in three representations, namely biology paired features, pairing in terms of feminine and masculine characteristics/qualities, and pronouns/damir referring to the male and female.
\end{abstract}

Perspektif al Quran mengenai ekologi berwawasan gender mengusung teori ekohumanis teosentris. Hal ini berdasarkan deskripsi al Quran mengenai interkoneksi dan interaksi harmonis antara manusia dengan dirinya sendiri, manusia dengan sesama manusia, manusia dengan alam raya dan manusia dengan Allah SWT, tanpa membedakan antara laki-laki dan perempuan. Metode penelitian ini adalah metode tafsir maudhu'i dan metode historis kritis kontekstual, dengan pendekatan kualitatif. Penelitian ini menemukan tiga isyarat identitas gender, yaitu keberpasangan secara biologis, berbagai istilah yang menunjuk kepada laki-laki dan perempuan dalam interaksinya dan

Ulul Albab Volume 16, No.2 Tahun 2015 
keseimbangan karakter feminin dan maskulin dalam setiap individu manusia. Hal ini mengindikasikan potensi intelektual dan emosional serta peran yang sama dalam interaksi sosialnya. Pada penelitian ini juga ditemukan karakter feminin dan maskulin dalam diri manusia yang digambarkan memiliki nilai positif dan negatif. Perbedaan karakter tersebut telah menjadi perdebatan akademis mengenai sterotip bagi laki-laki dan perempuan yang berimbas pada peran sosialnya. Sedangkan dalam ekologi alam, ditemukan tiga isyarat identitas gender, yaitu keberpasangan secara biologis, keberpasangan dari segi karakter dan kualitas feminin dan maskulin dan kata ganti/dhamir yang menunjuk kepada jenis kelamin laki-laki dan perempuan.

Keywords: natural ecology, human ecology, gender

\section{Pendahuluan}

Isu kerusakan lingkungan menjadi salah satu isu global yang meresahkan bagi masyarakat dunia saat ini. Beberapa riset tentang kerusakan bumi yang dilakukan oleh McElroy (Tucker dan Grim, 2001), WALHI (Sudarsono, 2007), dan Intergovernmental Panel on Climate Change (IPCC) pada akhir tahun 2007 melaporkan kerusakan lingkungan yang semakin menghawatirkan di seluruh belahan bumi. Berbagai macam bentuk kerusakan alam seperti bencana banjir, tanah longsor, pencemaran lingkungan, dan lainnya membuktikan faktor penyebab kerusakan lingkungan yang disebabkan prilaku manusia yang kurang harmonis dalam interaksinya dengan alam.

Hal ini disinyalir dari akibat pemahaman yang kurang komprehensif tentang pemahaman teks keagamaan, minimnya pengetahuan tentang alam, serta cara pandang manusia terhadap alam. Keseluruhan pemahaman dan cara pandang rigid (sempit) tersebut yang kemudian menimbulkan paradigma antroposentris. Paradigma antroposentris adalah paradigma yang memandang bahwa alam semesta tercipta untuk kebahagiaan hidup umat manusia sebagai pusatnya (Partanto dkk., 1994: 38). Paradigma yang kering nilai spiritual ini, memiliki implikasi logis terhadap ulah manusia dalam mengeksploitasi sumber daya alam serta perilaku manusia yang tidak menghormati eksistensi alam sebagai sesama makhluk ciptaan Tuhan. Selanjutnya, eksploitasi sumber daya alam identik dengan aktivitas laki-laki dalam dunia kerjanya, terlebih karakter maskulin yang umum dimiliki laki-laki seperti eksploitatif, arogan, dan ambisius, seakan mengabsahkan laki-laki sebagai jenis manusia yang dominan dalam berbagai interaksinya, baik dengan sesama manusia maupun lingkungan. 
Oleh karena sebab sikap dominatif laki-laki dalam interaksinya kepada sesama manusia dan lingkungan inilah, yang pada akhirnya menurut para tokoh ekofeminis seperti Nawal Amar dan Carolyn Merchant membuat lakilaki layak dipersalahkan sebagai aktor pemicu berbagai bentuk kerusakan lingkungan. Cara pandang ekofeminis ini adalah salah satu cara pandang yang unik dan menarik bagi penulis untuk dikembangkan dalam penelitian ini (Merchant, 1980: 183).

Keunikan cara pandang tokoh ekofeminis ini terdapat pada pergeseran isu seputar ketimpangan gender. Karena dalam beberapa dasawarsa terakhir, isu gender yang banyak mencuat yaitu seputar isu mengenai ketimpangan gender seperti dalam hak waris perempuan, perwalian, saksi, konstruk social, dan lainlain. Di antara tokoh yang memperdebatkan isu ini misalnya yaitu Laila Ahmad (Ahmad, 1992), Bonnie Fox (Fox, 1993), Barbara Freyer Stowasser (Stowasser, 1994), Nasr Hamid Abu Zaid (Zaid, 2000), dan Kamil Zahiri (Zahiri, 2002).

Menurut Simone de Beauvoir, jika menilik realitas sejarah, timbulnya berbagai paradigma tentang gender tidak terlepas dari sikap dan perlakuan diskriminasi laki-laki terhadap perempuan. Dalam isu ketimpangan gender, konsekuensi logis dari sikap diskriminatif kaum laki-laki terhadap perempuan inilah, yang mengakibatkan adanya paham feminis. Seandainya, tidak pernah terjadi ketimpangan gender dalam segala aspek kehidupan sosial dalam arti senantiasa dalam keadaan harmonis bagi lakilaki dan perempuan, pastilah tidak ada isu pemberontakan kaum feminis menuntut hak dan kewajiban serta "kesamaan" akses antara laki-laki dan perempuan dalam interaksi sosialnya pada dunia pendidikan, ekonomi, dan politik (Murata, 1996: 8).

Dalam kajian fikih misalnya, perempuan secara nyata kurang mendapat peran yang strategis dalam berbagai lini kehidupan, karena perempuan lebih diposisikan sebagai makhluk domestik. Sikap diskriminasi ini membuat perempuan menjadi pasif dan reseptif, praktis tidak memiliki kapabilitas dalam ranah publik. Hal ini merupakan akibat dari pola budaya dan sistem sosial masyarakat muslim Arab pada masa itu yang cenderung bersifat patriarkis, struktural dan subordinatif. Maka kajian Islam yang diformulasikan dalam fikih-pun banyak dipengaruhi oleh sistem sosial-budaya tersebut, dengan legitimasi berbagai dalil normatif, dengan penafsiran yang masih belum komprehensif (Kanafi, 2008: 1-2).

Sementara itu, dalam kajian ekologi manusia, budaya patriarki telah membawa laki laki pada terbentuknya karakter maskulin, sepertilebih aktif, 
kompetitif, ambisius, dan agresif dalam interaksinya kepada sesama manusia dan lingkungannya seperti yang diungkap sebelumnya.Hal inilah yang menjadikan laki-laki dianggap menjadi penyebab utama kerusakan lingkungan. Hipermasklinitas dan dominasi laki-laki terhadap perempuan disinyalir menjadi faktor penyebab laki laki juga bertindak sama terhadap bumi yang diidentikan dengan perempuan karena keduanya memiliki kesamaan karakter yang pasif dan submisif (Febriani, 2011: 8).

Demikian dalam kajian ekologi alam. Bumi memang lebih dinilai sebatas makhluk yang pasif dan reseptif yang tak lain merupakan representasi dari karakter feminin, karakter yang selama ini diidentikan dengan karakter perempuan (Armstrong, 1995: 32).

Itulah mengapa menurut para tokoh ekofeminis, pola interaksi laki laki yang arogan, diskriminatif, dan dominatif terhadap perempuan juga berimbas pada pola interaksi laki laki terhadap bumi dengan pola interaksi yang arogan dan eksploitatif. Ironisnya, hal ini masih diperburuk dengan mengakarnya paradigma antroposentris yang kering nilai spiritual dalam melegalkan arogansi manusia untuk mengeksploitasi alam dengan dalih kepentingan ekonomi. Cara pandang antroposentris terhadap alam, disinyalir membuat manusia melakukan apapun terhadap alam secara semena-mena. Memang di dalam al Quran dinyatakan bahwa alam diciptakan untuk dinikmati oleh manusia (QS. al Hajj: 65), tetapi jangan lupa, sebagai khalifah manusia juga menerima amanah konservasi untuk menjaga kelestariannya dan dilarang berlebih-lebihan (QS. al Rum: 44 dan QS. Ibrahim: 32).

Jika dipahami, permasalahan kerusakan lingkungan yang dihubungkan dengan sterotip antara laki-laki dan perempuan di atas, diakibatkan pola pikir yang masih sangat sempit dalam memandang dan mengklasifikasi antara karakter laki-laki dan perempuan. Oleh sebab itu, "Identitas Gender dengan kata sifat/ karakter feminin dan maskulin" dalam setiap individu manusia, yang ternyata dideskripsikan al Quran memiliki keseimbangan. Pemahaman ini diambil karena setiap ayat yang mengisyaratkan tentang karakter manusia didapati dalam bentuk umum sebagai indikasi bahwa ayat itu berlaku bagi laki-laki dan perempuan. Artinya, al Quran mempersilahkan kepada kecerdasan manusia untuk memilih karakter mana yang akan mempresentasikan kepribadiannya. Dengan demikian sterotip bagi laki-laki dan perempuan adalah pandangan yang keliru, karena baik karakter feminin dan maskulin dalam setiap individu manusia memiliki sisi positif dan negatif sebagaimana akan digambarkan secara ringkas dalam tabel di dalam makalah ini. 
Demikian dengan anggapan mengenai karakter yang dimiliki oleh masing masing makhluk ciptaan Allah SWT, yang ternyata jika ditelisik juga mengisyaratkan keseimbangan karakter feminin dan maskulin dalam setiap makhluk ciptaan Allah SWT. Bedanya antara karakter manusia dan suatu makhluk yang terdapat di alam raya yang dideskripsikan di dalam al Quran bahwa karakter suatu makhluk hanya memiliki karakter yang positif. Ini karena alam raya tidak akan membelot dari ketentuan yang sudah Allah SWT tetapkan atasnya. Manusia tentu dapat mengambil pelajaran dari tunduknya semua makhluk di alam raya yang mencipta harmoni untuk dapat mengemban tugas yang Allah SWT embankan kepada masing-masing makhluk. Oleh sebab itu pula, di dalam makalah ini penulis akan sekilas menjelaskan tentang keseimbangan karakter feminin dan maskulin yang dimikili oleh setiap individu manusia dan segenap makhluk di alam raya. Untuk contoh makhluk di alam raya penulis mengambil satu sampel dari keberpasangan antara langit dan bumi.

\section{Wawasan Gender dalam Ekologi Alam}

Sebagaimana diungkap di awal bahwa di dalam disertasi penulis telah ditemukan sedikitnya ada tiga isyarat identitas gender pada ekologi alam, yaitu: 1) keberpasangan secara biologis, 2) keberpasangan dari segi karakter dan kualitas feminin dan maskulin, dan 3) kata ganti/dhamir yang menunjuk kepada jenis kelamin laki-laki (mudhakkar majazi) dan jenis kelamin perempuan (mu'annath majazi).

Pembahasan dalam tulisan ini lebih difokuskan kepada pembahasan singkat mengenai identitas gender pada ekologi alam yang kedua, yaitu berpasangan dari segi karakter feminin dan maskulin. Salah satu karakteristik feminin yang dimiliki bumi adalah bumi diidentikan dengan ibu karena bumi dinilai memiliki sifat kasih sayang (memberikan kehidupan bagi manusia tanpa meminta balasan), dan lemah lembut karena memperbolehkan manusia menggunakan berbagai fasilitas yang ada padanya (QS. al Hajj: 65), bumi menyenangkan karena berbagai makhluk dapat bernaung dengan tenang di dalamnya (QS. al Mu'min: 64), manusia dibuat dari bumi/tanah (QS. Hud: 61) dan asal dan tempat manusia hidup di bumi/produktif (QS. Thaha: 55), berbagai ciri khas tersebut merupakan beberapa ciri dari karakter feminin.

Wawasan gender dalam ekologi alam menurut perspektif al Quran, di antaranya terukir dalam relasi bumi (yang memiliki karakter pasif dan reseptif, yaitu kualitas feminin) dan langit (yang memiliki karakter aktif dan dominan, 
yaitu kualitas maskulin) di dalam al Quran. Pasangan yang tidak akan exis tanpa kehadiran salah satu dari keduanya ini, adalah gambaran keseluruhan kosmos yang bersanding harmonis dan komplementer dalam karakter dan mengemban fungsinya masing masing. Interkoneksi antara kedua pasangan inilah yang memberikan kehidupan bagi seluruh makhluk Allah SWT yang bernaung di dalamnya (Kanafi, 2008: 11).

Di dalam al Quran pasangan yang paling sering disebut yang dapat ditafsirkan sebagai gambaran keseluruhan kosmos adalah langit dan bumi. Sejumlah ayat mengisyaratkan bahwa segala sesuatu di alam raya dicakup oleh keduanya ini. Setidaknya, dapat dikatakan bahwa langit dan bumi disebut sebagai representator alam/dua titik acuan dasar di dunia ini. Isyarat ini dapat ditemukan dalam ayat yang berbunyi:

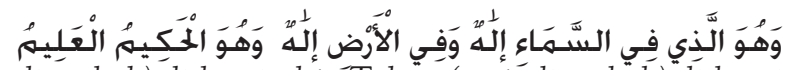

"Dan Dialah Tuhan (yang disembah) di langit dân Tuhan (yañg disembah) di bumi dan Dia-lah yang Maha Bijaksana lagi Maha Mengetahui" (QS. al Zukhruf: 84).

Menurut Murata, kata langit (sama') digunakan di dalam al Quran sebanyak 120 kali dalam bentuk tunggal dan jamak 190 kali, dan kata bumi (ardh) digunakan 460 kali. Selain itu, ungkapan langit dan bumi dikemukakan lebih dari 200 kali. Penjajaran yang terus menerus dari kedua istilah itu (belum lagi interelasi konseptual mereka) membuat mustahil untuk menyebutkan yang satu tanpa menyertakan yang lain dalam pembahasan yang lain. Selanjutnya, ia mengingatkan bahwa kata langit (sama') adalah yang lebih tinggi, paling atas, bagian dari dalam sesuatu. Itu juga digunakan dalam arti angkasa, awan, hujan, dan karunia.Sebaliknya, akar verbal dari (ardh), berarti berusaha dan menghasilkan, membuahkan hasil, bersikap lemah lembut, merendah, menyerah, dan secara alamiah terpanggil untuk berbuat baik. Ardh (QS. al Baqarah: 22) adalah tempat tinggal manusia, tanah, lantai, dan segala sesuatu yang rendah (Murata, 1992: 165-169).

Sangat menarik memahami fenomena perkawinan alam yang begitu indah digambarkan di dalam al Quran. Ketika bumi (dianalogikan seperti ibu) dalam keadaan kering, lalu langit (dianalogikan seperti bapak) menumpahkan air dengan suka cita karena cintanya, hingga dari air yang ditumpahkan langit ke bumi itu, keluarlah spesies/makhluk lain yang dapat dianalogikan dengan anak (QS. Luqman: 24). Inilah yang disebut perkawinan kosmos. 
Teori perkawinan makrokosmik ini pertama kali menemukan artikulasinya yang jelas pada tulisan Ibnu Arabi (w. 638 H/1240 M) terutama dalam kitabnya al Futuhat al Makkiyyah (Arabi, 2009: 65).Tetapi, penjelasannya yang paling rinci dan sistematis dapat ditemukan dalam tulisan Shadr al Din al Qunawi (w.1274 M).Al Qunawi menjelaskan lima tingkat perkawinan makrokosmik ini: 1) tak terlihat (ghaib), 2) rohaniah, 3) alamiah, 4) elemental, dan 5) manusiawi (Kartanegara, 2006: 49-50).

Relasi gender dalam ekologi juga digambarkan di dalam al Quran, ketika Allah SWT mengisyaratkan bahwa Dia menciptakan segala sesuatu berpasang pasangan dalam kosmos:

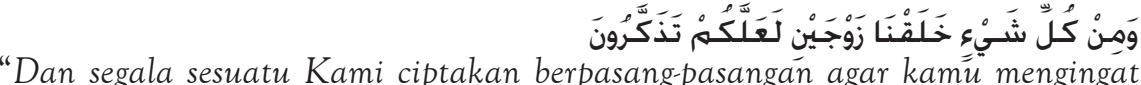
(Kebesaran Allah)” (QS. al Dhariyat: 49).

Menurut Muhammad Quraish Shihab, kata (أزواج)azwaj/pasangan pada ayat ini dalam pandangan para ahli bahasa seperti al Raghib al Ashfahani, digunakan untuk masing masing dua hal yang berdampingan (bersamaan), baik jantan maupun betina, binatang, manusia, dan juga digunakan menunjuk kedua yang berpasangan. Dia juga digunakan menunjuk hal yang sama bagi selain binatang, seperti alas kaki. Selanjutnya al Raghib menjelaskan bahwa keberpasangan tersebut bisa akibat kesamaan dan bisa juga karena bertolak belakang. Dalam ayat al Quran, kata (أزواج)azwaj/pasangan dalam pengertian umum, bukan hanya untuk makhluk hidup. Dari sini ada malam ada siang, ada senang ada susah, ada atas ada bawah, demikian seterusnya. Semua (selama dia makhluk) memiliki pasangan. Hanya Sang Khalik, Allah SWT yang tidak ada pasangan-Nya, tidak ada pula sama-Nya. Dari segi ilmiah, terbukti bahwa listrikpun berpasangan, ada arus positif dan arus negatif, demikian pula atom, yang tadinya diduga merupakan wujud yang terkecil dan tidak dapat terbagi, ternyata iapun berpasangan. Atom terdiri dari elektron dan proton (Shihab, 2005: 538-539).

Dari ayat ini dapat dipahami bahwa setiap kali Allah SWT menciptakan sesuatu, Dia menciptakannya secara berpasang pasangan, sebagai dua benda yang dikaitkan satu sama lain atau berlawanan satu sama lain. Segalanya diciptakan dari dua realitas yang berbeda namun komplementer (saling melengkapi). 


\section{Identitas Gender dengan Karakter Maskulin dan Feminin pada Suatu Makhluk}

Mengenai identitas gender dalam ekologi alam berdasarkan karakter feminin dan maskulin yang disandang suatu makhluk, penulis mengajukan representasi 5 (lima) jenis pasangan makhluk yang diungkapkan al Quran, dalam penunjukkan identitas gender berdasarkan segi karakter feminin dan maskulin yang dimiliki, yaitu pasangan: 1) langit dan bumi, 2) daratan dan lautan, 3) matahari dan bulan, 4) awan dan angin, dan 5) api dan air. Keseluruhan pasangan ini, umumnya menunjukkan identitas gender dalam hal partnership/ keberpasangan dalam karakter yang koperatif dan komplementer.

Penulis memang belum mendapati kajian khusus yang membagi karakter maskulin dan feminin dalam ekologi. Namun sebagai sebuah landasan secara umum, penulis mendapati karangan Sachiko Murata yang mengklasifikasikan karakater feminin dan maskulin dalam mikrokosmik.Murata mengemukakan contoh pembagian karakter feminin dan maskulin, dalam versi Abd al Razzaq Kashani (Kashani, 1968: 638-639). Berikut pembagian karakter maskulin (yang) dan feminin (yin) dalam mikrokosmik versi Kashani:

Tabel 1. Pembagian Karakter Feminin dan Maskulin dalam Mikrokosmik Versi Kashani

\begin{tabular}{ccc} 
No. & Karakter maskulin $(\boldsymbol{y a n g})$ & Karakter feminin $(\boldsymbol{y i n})$ \\
\hline 1 & Langit & Bumi \\
\hline 2 & Tak terlihat & Terlihat \\
\hline 3 & Dominion & Kerajaan \\
\hline 4 & Perintah & Penciptaan \\
\hline 5 & Tinggi & Rendah \\
\hline 6 & Terang & Gelap \\
\hline 7 & Lembut & Padat \\
\hline 8 & Ruhaniah & Jasmaniah \\
\hline 9 & Supraindrawi & Indrawi
\end{tabular}

Sumber: Mikrokosmik versi Kashani (Kashani, 1968: 638-639)

Pasangan istilah yang sejajar di atas, menjalin suatu hubungan jelas yang dapat dipahami dalam pengertian sifat sifat yang bertentangan. Secara umum istilah pertama mewakili sifat sifat yang (maskulin) dan istilah yang kedua mewakili sifat sifat yin (feminin) (Murata, 1992: 131). Dari tabel 1 juga dapat dipahami bahwa karakter feminin dan maskulin tidak selalu dalam artian karakter maskulin identik dengan keras, tegas, dan aktif. Demikian sebaliknya 
dengan karakter feminin, tidak selamanya dalam artian pasif dan reseptif.

Selain itu, menurut Murata memang terjadi hubungan yang berubah ubah dalam mikrokosmik.Sejalan dengan istilah-istilah al Quran tentang yang tak terlihat dan terlihat, atau langit dan bumi. Beberapa ahli seperti Kasyani menggunakan pasangan lain dalam istilah yang digunakan di dalam al Quran, seperti dominion dan kerajaan, atau perintah dan penciptaan. Biasanya, dunia yang terlihat dianggap sama dengan lingkup benda benda jasmaniah dan inderawi, sementara dunia yang tidak terlihat mencakup benda benda ruhaniah dan nonindrawi. Murata juga menyatakan,"benda benda menjadi dapat dibedakan melalui lawan kebalikannya".

Lokus perwujudan suatu benda adalah kebalikannya, jadi masingmasing kebalikan membantu kebalikannya (al Rumi, 1967: 3761). Tidak ada kebaikan yang dapat diketahui tanpa kebalikannya. "Setelah menerima satu pukulan, anda akan tahu rasanya sebuah belaian” (al Rumi, 1966: V 599). Artinya "Tidak ada yang mutlak di dalam penciptaan, sebab tidak ada yang berdiri sendiri (Murata, 1996: 131). Setiap sesuatu Allah SWT ciptakan dalam dualitas yang berlawanan namun komplementer. Suatu makhluk justru dapat menunjukkan eksistensinya, jika ia memiliki pasangan.

Selanjutnya, keberpasangan dalam hal karakter feminin dan maskulin dalam ekologi alam diketahui dari fungsi dan peran yang dideskripsikan al Quran, yang juga ternyata memiliki keseimbangan antara karakter feminin dan maskulin pada masingmasing makhluk yang dijadikan sampel/representator. Dalam menemukan pasangan dalam bentuk karakter pada kajian ekologi alam dalam perspektif al Quran ini, penulis mencoba mencari pasangan yang sering al Quran sandingkan secara bersamaan dalam penyebutannya sebagai suatu indikasi keberpasangan, sekaligus indikasi adanya wawasan gender yang diisyaratkan al Quran, karena masing-masing pasangan memiliki karakter yang berlawanan.

Namun demikian, perlu digarisbawahi bahwa ada perbedaan mendasar bagi klasifikasi karakter feminin dan maskulin dalam ekologi manusia dan alam. Jika dalam ekologi manusia, karakter feminin dan maskulin memiliki nilai atau sisi positif dan negatif, tidak demikian halnya dengan ekologi alam. Hal ini mengingat bahwa alam raya patuh dan tunduk pada seluruh ketetapan yang Allah SWT berikan atasnya, seluruh makhluk yang berada di alam raya tidak pernah menyalahi kodrat yang diberikan Allah SWT kepada mereka. Jika terdapat karakter negatif seperti alam sebagai media pemberian azab, itu merupakan respon alam dari ulah tangan manusia sendiri (QS. al Anfal: 58). Bencana alam dapat dikatakan sebagai revitalisasi bumi (Way, 2011: 
52), sedangkan kerusakan lingkungan adalah ulah manusia yang menuntut manusia untuk kembali memperbaikinya.

Berikut contoh identitas gender dalam keperpasangan secara karakter/ sifat pada langit dan bumi.

Tabel 2. Klasifikasi Karakter Langit dalam Al Quran

\begin{tabular}{llll}
$\begin{array}{l}\text { No } \\
1\end{array}$ & $\begin{array}{l}\text { Klasifikasi karakter } \\
\text { Atap/diatas }\end{array}$ & $\begin{array}{c}\text { No ayat dan surat } \\
2 / 22,40 / 64 .\end{array}$ & $\begin{array}{l}\text { Keterangan karakter } \\
\text { dominatif-maskulin }\end{array}$ \\
\hline 2 & Alat pemberi azab & $7 / 162,29 / 34$. & $\begin{array}{l}\text { instrumental-feminin } \\
\text { instrumental-feminin }\end{array}$ \\
& Alat pemberi petaka & $2 / 59$. & aktif dan informatif- \\
\hline 3 & Salah satu tanda & $6 / 75,10 / 101$. & maskulin \\
\hline & kebesaran Allah dan & & \\
& sumber sains & & pasif-feminin \\
\hline 4 & Dibina & $79 / 27$. & pasif-feminin \\
\hline 5 & Dijaga & $15 / 17,72 / 8-9$. & pasiffeminin \\
\hline 6 & Dilindungi & $37 / 7$. & pasif-feminin \\
\hline 7 & Pemah & $69 / 16$. & submisif-feminin \\
\hline 8 & Mengandung hujan & $84 / 2$. & produktif-maskulin
\end{tabular}

Sumber: Data Diolah Berdasarkan Al Quran

Sebagaimana tabel 2, dapat diketahui bahwa langit tidak hanya memiliki karakter maskulin, akan tetapi juga memiliki karakter feminin. Dari sini dapat diketahui bahwa, al Quran mengisyaratkan langit memiliki keseimbangan karakter feminin dan maskulin.Karakter maskulin pada langit terlacak dari posisinya yang di atas (dominan) serta potensi informatifnya sebagai sumber sains, serta produktifitas langit yang merupakan ciri dari karakter maskulin.

Selain itu, langit juga memiliki karakter feminin seperti lemah dan senantiasa dijaga, dibina dan patuh terhadap ketentuan AllahSWT yang merupakan indikasi dari karakter feminin. Dari tabel 2 di atas, penulis tertarik pada QS. al Baqarah ayat 22:

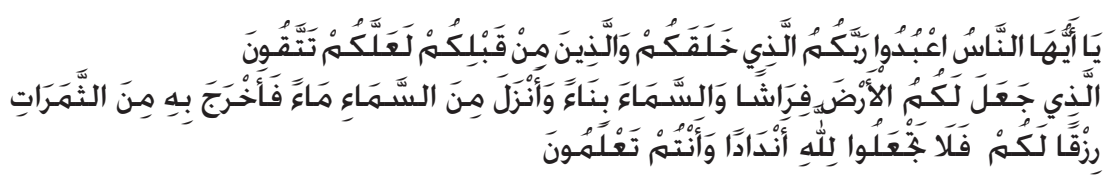

"Dialah yang menjadikan bumi sebagai hamparan bagimu dan langit sebagai atap, dan 
Dia menurunkan air (hujan) dari langit, lalu Dia menghasilkan dengan hujan itu segala buah-buahan sebagai rizki untukmu; karena itu janganlah kamu Mengadakan sekutusekutu bagi Allah, Padahal kamu mengetahui." 22" (QS. al Baqarah: 21-22).

Menurut Fakhru al Razi ada hikmah yang dapat diambil dibalik rentetan penyebutan obyek ciptaan Allah SWT pada ayat di atas. Pertama, Allah SWT menyebutkan penciptaan diri manusia. Kedua, berasal dari kedua orang tua. Ketiga, penciptaan bumi sebagai daratan yang menghampar. Keempat,langit sebagai atap yang dipelihara dan Kelima,hasil yang didapatkan dari proses perkawinan langit dan bumi, berupa berbagai macam tumbuhan.

Sebab runtutan dari kelima poin di atas, mengandung beberapa alasan. Pertama, bahwa yang paling diketahui/dikenal oleh manusia adalah dirinya sendiri. Oleh sebab itu, penyebutan tentang diri manusia secara pribadi lebih ditekankan di awal. Kedua, yaitu orang tua. Karena dari perkawinan kedua orang tua, manusia dapat terlahir ke dunia, ada kedekatan emosional antara anak dan orangtua yang akan selalu dipujanya. Ketiga, bumi sebagai tempat tinggal manusia. Pada umumnya, manusia jauh mengenal bumi lebih baik daripada langit. Keempat,langit sebagai atap bumi. Secara bahasa, kata al sama' berarti segala sesuatu yang berada di atas yang menaungi di bawahnya. Sedangkan secara istilah, al sama' adalah angkasa luas yang tinggi di atas bumi, berfungsi sebagai pembungkus bumi dan terdiri dari beberapa lapis gas ( $\mathrm{Al}$ Najar, 2001: 10). Biasanya, manusia lebih mengenal yang lebih dekat (bumi) baru kemudian mempelajari selainnya yang lebih jauh (langit). Sedangkan yang kelima, didahulukannya penyebutan langit daripada bumi, karena langit memiliki peran penting dalam menurunkan air hujan agar dapat membasahi bumi, yang akhirnya dari air ini akan menumbuhkan berbagai macam spesies tumbuhan sebagai bahan makanan dan kebutuhan hidup manusia (al Razi, 1995: 10).

Dari ayat ini, dapat ditangkap adanya deskripsi tentang interaksi harmonis dalam ekologi manusia dan ekologi alam yang diisyaratkan al Quran. Rentetan dari penyebutan jenis ciptaan Allah SWT mengajak manusia untuk dapat lebih mengenal dirinya sendiri, orang tua sebagai orang terdekat yang berjasa melahirkannya di dunia, bumi sebagai tempat tinggal mereka, langit sebagai atap hidup di dunia, serta manfaat yang dapat dinikmati manusia dari proses perkawinan antara langit dan bumi berupa berbagai macam jenis tumbuhan yang menghasilkan buah dan makanan. Sebagai satu kesatuan dari ekosistem yang tidak terpisahkan di bumi ini, al Quran mengajak manusia agar menyadari akan kebesaran Allah SWT dalam menciptakan segala sesuatu. Salah satu pelajaran 
terpenting lain dari perpaduan ayat ini adalah manusia mengetahui bahwa dari proses perkawinan dari kedua orang tua menghasilkan dirinya, sementara perkawinan langit dan bumi menghasilkan berbagai macam tumbuhan di bumi. Berikut gambar tabel mengenai klasifikasi karakter bumi:

Tabel 3. Klasifikasi Karakter Bumi

\begin{tabular}{|c|c|c|c|}
\hline No & Klasifikasi karakter & No surat dan ayat & Keterangan karakter \\
\hline \multirow[t]{5}{*}{1} & Hamparan luas & $2 / 22,20 / 53,78 / 6$ & nurturing-feminin \\
\hline & Dihamparkan & $\begin{array}{l}13 / 3,15 / 9,50 / 7 \\
51 / 48,79 / 30 \\
88 / 20,71 / 19-20\end{array}$ & menyenangkan, feminin \\
\hline & Tampak datar & $18 / 47$ & Menyenangkan,feminin \\
\hline & Luas & $29 / 56$ & Menyenangkan, feminin \\
\hline & Jalan yang luas & $20 / 53,21 / 31$ & Menyenangkan, feminin \\
\hline 2 & $\begin{array}{l}\text { Bahan penciptaan } \\
\text { manusia }\end{array}$ & $11 / 61$ & Instrumental, feminin \\
\hline \multirow[t]{6}{*}{3} & $\begin{array}{l}\text { Tempat tumbuh } \\
\text { berbagai macam } \\
\text { spesies tumbuhan } \\
\text { di dalamnya, yang } \\
\text { memiliki kelebihan } \\
\text { dan rasa masing- } \\
\text { masing }\end{array}$ & $13 / 3-4$ & Produktif-maskulin \\
\hline & Ditumbuhi tanaman & $\begin{array}{l}23 / 19,26 / 7,36 / 33- \\
35,50 / 7,86 / 12\end{array}$ & Produktif, maskulin \\
\hline & $\begin{array}{l}\text { Sumber kehidupan } \\
\text { makhluk }\end{array}$ & $15 / 20$ & Aktif, maskulin \\
\hline & $\begin{array}{l}\text { Asal dan tempat } \\
\text { manusia hidup }\end{array}$ & $20 / 15$ & Empatik, feminin \\
\hline & $\begin{array}{l}\text { Tempat berkumpul } \\
\text { manusia yang hidup } \\
\text { dan yang mati }\end{array}$ & $77 / 25-26$ & Empatik, feminin \\
\hline & $\begin{array}{l}\text { Tempat menetap dan } \\
\text { berjalan-jalan }\end{array}$ & $40 / 64,43 / 10$ & Instrumental, feminin \\
\hline 4 & Mudah dijelajahi & $67 / 15$. & Pasif, feminin \\
\hline
\end{tabular}




\begin{tabular}{|llll|}
\hline No & Klasifikasi karakter & No surat dan ayat & Keterangan karakter \\
\hline 5 & $\begin{array}{l}\text { Dihidupkan dengan } \\
\text { air hujan }\end{array}$ & $\begin{array}{l}16 / 65,22 / 5,41 / 39, \\
30 / 24 .\end{array}$ & Pasif-feminine \\
\hline 6 & $\begin{array}{l}\text { Sarana mempelajari } \\
\text { sejarah peradaban } \\
\text { manusia }\end{array}$ & $30 / 19$. & Informatif- maskulin \\
\hline 7 & $\begin{array}{l}\text { Salah satu sumber } \\
\text { sains }\end{array}$ & $51 / 20$. & Informatif- maskulin \\
\hline 8 & $\begin{array}{l}\text { Patuh pada ketentuan } \\
\text { Allah }\end{array}$ & $84 / 5$. & Submisif-feminin \\
\hline
\end{tabular}

Sumber: Data Diolah Berdasarkan Al Quran

Dari beberapa karakter bumi yang dapat diketahui dari tabel 3 di atas, diketahui bahwa karakter bumi adalah karakter yang menyenangkan, tempat yang luas dan nyaman bagi makhluk yang bernaung didalamnya (pemelihara seperti seorang ibu), patuh, dan pasif karena membutuhkan air untuk menghidupinya (reseptif). Sebagai salah satu sarana manusia untuk mendapatkan ilmu pengetahuan, bumi dapat dikatakan sebagai edukator yang menjadi salah satu ciri feminin.

Namun, Bumi juga memiliki karakter maskulin karena bumi menjadi salah satu sumber sains bagi manusia, bumi juga produktif dalam menghasilkan berbagai kebutuhan hidup manusia. Bumi juga dikatakan sebagai informan sejarah bagi manusia lewat berbagai benda bersejarah yang masih dapat diteliti dan dipelajari manusia. Dari sini dapat diketahui bahwa bumi memiliki keseimbangan karakter feminin dan maskulin dalam dirinya. Allah SWT mengisyaratkan hal ini dengan berfirman:

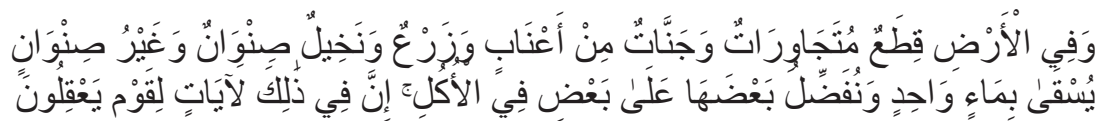

"Dan di búmi ini terdapat bagian-bagian yang berdampingan, dan kebunkebun anggur, tanaman-tanaman dan pohon korma yang bercabang dan yang tidak bercabang, disirami dengan air yang sama. Kami melebihkan sebahagian tanam-tanaman itu atas sebahagian yang lain tentang rasanya. Sesungguhnya pada yang demikian itu terdapat tanda-tanda (kebesaran Allah) bagi kaum yang berfikir" (QS. al Ra'd: 4).

Ayat di atas mengindikasikan tentang potensi bumi yang sangat produktif dalam menghasilkan berbagai macam jenis tumbuhan, baik yang hasilnya dapat 
digunakan untuk bahan makanan ataupun jenis tumbuhan yang bermanfaat untuk menopang kebutuhan hidup manusia yang lain. Tanah sebagai media tanam yang baik digambarkan al Quran memiliki berbagai macam jenis. Menurut Thanthawi, kata qith'un mutajawirat pada ayat di atas sebagai indikasi tentang adanya beberapa jenis tanah. Di antaranya, ada yang empuk dan keras, ada yang bagus untuk ditanami dan ada yang tidak baik ditanami tanaman (tanah yang tidak produktif) (Jauhari, tt: 81).

Ayat ini dipahami sebagai adanya isyarat ilmu tentang tanah (geologi dan geofisika) dan ilmu lingkungan hidup (ekologi) serta pengaruhnya terhadap sikap tumbuhtumbuhan. Secara ilmiah, telah diketahui bahwa tanah persawahan terdiri atas butir butir mineral yang beraneka ragam sumber, ukuran, dan susunannya, demikian juga air yang bersumber dari hujan; udara, zat organik yang berasal dari limbah tumbuh-tumbuhan dan makhluk hidup lainnya yang ada di atas maupun lapisan tanah. Lebih dari itu, terdapat pula berjuta juta makhluk hidup yang amat halus yang tidak dapat dilihat dengan mata telanjang, karena ukurannya yang sangat kecil. Jumlahnya pun sangat bervariasi, berkisar antara puluhan juta sampai ratusan juta pada setiap satu gram tanah pertanian. Sifat-sifat tanah yang bermacam-macam itu, baik secara kimia, fisika maupun secara biologi, menunjukkan kemahakuasaan Allah SWT, sebelum ilmuan benar benar berbeda dari satu jengkal ke satu jengkal lainnya (Shihab, 2005: 330-331).

Pada tabel 3 di atas, selain klasifikasi karakter feminin bumi seperti karakter bumi yang menyenangkan, dapat diketahui juga bahwa al Quran mengisyaratkan bumi yang juga memiliki karakter maskulin, seperti aktif dan informatif. Dari sini dapat dipahami bahwa terdapat keseimbangan karakter maskulin dan feminin yang dimiliki oleh bumi.

\section{Wawasan al Quran tentang Keseimbangan Karakter Feminin dan Maskulin dalam Setiap Individu Manusia}

Identifikasi karakter feminin dan maskulin bagi manusia dalam perspektif al Quran pernah dilakukan oleh Murata dengan menyatakan karakter maskulin memiliki ciri has yang aktif dan melimpahkan, sedangkan karakter feminin memiliki ciri khas pasif, menerima, dan berserah diri. Menurut Murata kedua karakter ini ada dalam setiap individu manusia. Hirarki vertikal dalam diri manusia adalah, ruh, jiwa (nafs), akal, dan raga. Ruh adalah cahaya keilahian yang harus diraih oleh setiap manusia. jiwa yang "meyerahkan" dirinya pada yang "lebih rendah" (materi, dunia, sifat sifat negative, dan sebagainya) adalah 
sifat "feminin yang negatif" (sifat yang menerima dan menyerah tidak mampu melawan yang rendah). Sedangkan jiwa yang "menyerahkan" dirinya pada yang "lebih tinggi", yaitu akal, ruh, dan Tuhan adalah "sifat feminin positif" (menyerah hanya pada yang lebih tinggi).

Sebaliknya, jiwa yang "berkuasa", mendominasi, meninggikan diri, mempertuhankan diri, adalah sifat "maskulin negatif". Sementara jiwa yang ingin "mengalahkan nafsu amarah" dan ingin naik mencapai nafsu mutmainnah yang damai bersama Tuhan adalah sifat "maskulin positif".Jiwa yang tenang dan damai bersama Tuhan ini adalah jiwa kesatria yang telah melebur dengan ruh dan akal. Manusia ini telah menjadi ruh aktif (maskulin positif) yang dapat mengontrol dan menguasai jiwa dan raga agar selaras dengan cahaya ruh dan akal (Murata, 1996: 269).

Dari penjelasan Murata di atas dapat dipahami bahwa, bagi jiwa (nafs), baik buruk nilainya tergantung pada pilihan sisi/nilai positif atau negatif dari karakter maskulin dan feminin yang dipilih manusia untuk merepresentasikan jiwa atau karakternya. Jiwa yang mengalah pada yang lebih rendah/nafsu, maka dikategorikan sebagai jiwa yang berkarakter feminin negatif.Sedang jiwa yang mengalah pada yang lebih tinggi yaitu akal ruh dan Tuhan, maka dikategorikan dalam karakter feminin positif. Sebaliknya, jiwa yang dominatif dan menuhankan diri, dikategorikan dalam maskulin negatif. Sedang jiwa yang mengalahkan nafsu amarah/amarah bi al su', dikategorikan pada maskulin positif.

Untuk lebih menyederhanakan tentang karakter manusia yang memiliki nilai dan sisi positif dan negatif dalam penelitian ini, penulis cenderung menggunakan istilah yang digunakan oleh Iman Ghazali dalam membagi dua jenis karakter, yaitu: karakter yang baik (husn alkhulq) dan karakter yang buruk (su' alkhulq) sebagaimana diungkap di depan.

Namun, sesuai dengan isyarat yang juga ditangkap dari al Quran mengenai dua jenis karakter manusia pada QS. Al Shams: 7-8 yang menggunakan kalimat "fujuraha wa taqwaha" atau karakter yang buruk dan baik, maka pembagian dua jenis karakter dibagi menjadi dua, yaitu: "alnafsu al fujuriyyah"(karakter yang buruk) dan "alnafsu al taqwa'iyyah" (karakter yang baik). Isyarat ini diambil dari ayat yang berbunyi:

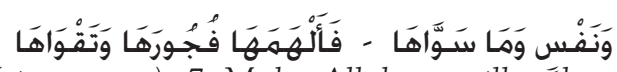

"Dan jiwa serta penyempurnaannya (ciptaannya), 7. Maka Allah mengilhamkan kepada jiwa itu (jalan) kefasikan dan ketakwaannya" (QS. al Shams: 7-8). 
Hamka menafsirkan kata "fujuraha wa taqwaha" pada ayat di atas, dengan kepribadian/karakter manusia yang buruk dan yang baik (Amrullah, 2000: 174). Dari penjelasan Hamka ini, dapat dipahami bahwa manusia memiliki sifat yang baik dan buruk atau sifat yang memiliki nilai positif dan negatif. Diungkapkannya redaksi ayat di atas dalam bentuk umum, dapat dipahami pula bahwa sifat baik dan buruk, bisa dimiliki oleh laki-laki dan perempuan secara umum.

Selanjutnya, perlu dipetakan tentang pembagian karakter maskulin dan feminin dalam diri manusia, kedua karakter ini sebagaimana isyarat ayat di atas, sama-sama memiliki nilai positif dan negatif. Karakter maskulin bagi manusia adalah karakter yang berhubungan dengan sifat kemuliaan. Karakter maskulin yang positif adalah karakter yang bijaksana dan kesatria atau karakter yang dapat mengalahkan nafsu amarah. Oleh sebab itu, karakter maskulin adalah karakter yang juga berhubungan dengan logika. Dengan demikian, berbagai karakter yang berhubungan dengan karakter yang aktif, independen, obyektif, responsif, progresif, dan visioner masuk dalam kategori karakter maskulin. Sedang karakter maskulin negatif adalah karakter manusia yang dominatif dan menuhankan diri. Maka, berbagai karakter yang berhubungan dengan karakter manusia yang arogan, masuk dalam ketegori maskulin negatif.

Karakter feminin adalah karakter berhubungan dengan sifat keindahan. Jika di atas telahdikatakan bahwa karakter feminin yang positif adalah karakter yang mengalah pada yang lebih tinggi yaitu akal dan ruh, artinya karakter ini adalah karakter yang berhubungan dan berdasarkan pertimbangan hati (intuisi/emosi). Oleh sebab itu, berbagai karakter manusia yang berhubungan dengan perasaan kasih sayang, submisif, keteraturan, dan kreatifitas masuk dalam kategori karakter feminin positif. Karakter feminin yang negatif adalah karakter yang mengalah pada yang lebih rendah, yaitu hawa nafsu. Maka berbagai karakter yang mengalah pada emosi negatif seperti subyektif dan pasif masuk dalam kategori feminin negatif.

Selanjutnya, berikut analisa penulis mengenai isyarat ekualitas antara karakter feminin dan maskulin yang memiliki sisi dan nilai positif dan negatif dalam setiap individu manusia: 
Tabel 4. Klasifikasi Identitas Gender dalam Ekologi Manusia dengan

Keseimbangan Karakter Feminin dan Maskulin dalam setiap Individu

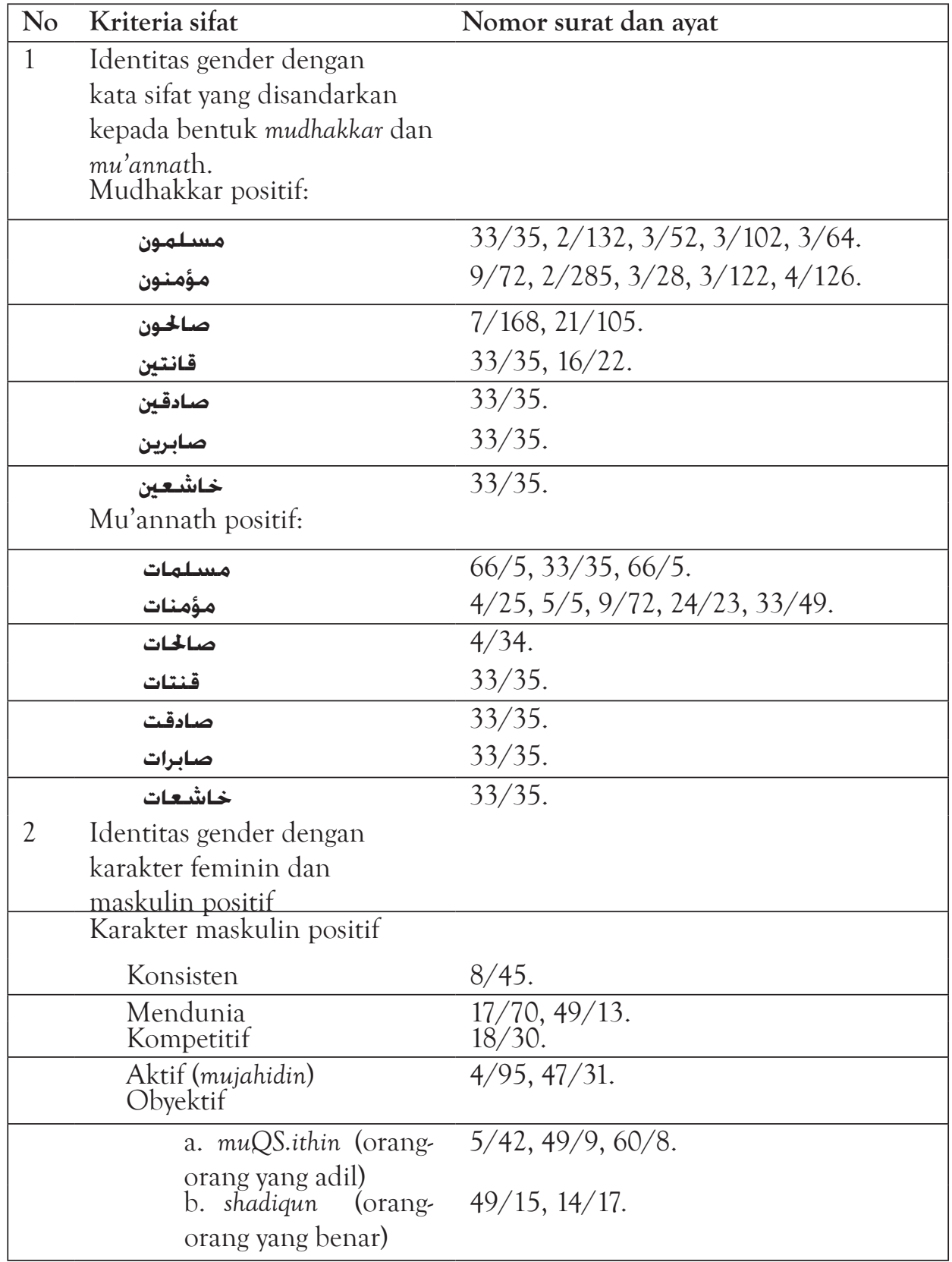

Ulul Albab Volume 16, No.2 Tahun 2015 


\begin{tabular}{|c|c|c|}
\hline No & Kriteria sifat & Nomor surat dan ayat \\
\hline & $\begin{array}{l}\text { Logis (ya'qilun) } \\
\text { Independen }\end{array}$ & $\begin{array}{l}2 / 164,13 / 4,16 / 12,29 / 35 . \\
8 / 53 .\end{array}$ \\
\hline & $\begin{array}{l}\text { Petualang (intasyara) } \\
\text { Komunikatif }\end{array}$ & $\begin{array}{l}62 / 9 \\
3 / 159\end{array}$ \\
\hline & $\begin{array}{l}\text { Keseimbangan rasio dan } \\
\quad \text { rasa } \\
\text { Kemampuanmemimpin }\end{array}$ & 49/9-10. \\
\hline & $\begin{array}{l}\text { Lebih merdeka (yantashirun/ } \\
\text { membela diri) } \\
\text { Lebih bebas bicara }\end{array}$ & $42 / 39$ \\
\hline & $\begin{array}{l}\text { Visioner } \\
\text { Responsif }\end{array}$ & $\begin{array}{l}3 / 104 \\
3 / 114\end{array}$ \\
\hline & $\begin{array}{l}\text { Progressif } \\
\text { Produktif }\end{array}$ & $\begin{array}{l}17 / 36 \\
16 / 97\end{array}$ \\
\hline & Karakter feminin positif & \\
\hline & Taat/Submisif & $8 / 46,2 / 21,1 / 5$ \\
\hline & $\begin{array}{l}\text { Sabar } \\
\text { Empati }\end{array}$ & $\begin{array}{l}8 / 66 . \\
33 / 29 .\end{array}$ \\
\hline & $\begin{array}{l}\text { Pemurah } \\
\text { Tawakal }\end{array}$ & $\begin{array}{l}57 / 18 . \\
12 / 67,14 / 12,39 / 38,3 / 159 .\end{array}$ \\
\hline & $\begin{array}{l}\text { Taqwa (rasa takut) } \\
\text { Senang memberi }\end{array}$ & $\begin{array}{l}2 / 177,8 / 34,13 / 35,25 / 15,39 / 33, \\
47 / 15 . \\
2 / 3 .\end{array}$ \\
\hline & $\begin{array}{l}\text { Ikhlas } \\
\text { Memohon ampun }\end{array}$ & $\begin{array}{l}12 / 24,15 / 40,37 / 40,37 / 74 . \\
51 / 18 .\end{array}$ \\
\hline & $\begin{array}{l}\text { Bersyukur } \\
\text { Menerima saran/bijak }\end{array}$ & $\begin{array}{l}86 / 3 \\
2 / 206\end{array}$ \\
\hline & $\begin{array}{l}\text { Pemaaf } \\
\text { Egaliter }\end{array}$ & $\begin{array}{l}3 / 159 . \\
49 / 13 .\end{array}$ \\
\hline & $\begin{array}{l}\text { Kreatif } \\
\text { Tenang }\end{array}$ & $\begin{array}{l}13 / 11 \\
33 / 35,66 / 5,89 / 27 .\end{array}$ \\
\hline 3 & \begin{tabular}{l}
\multicolumn{1}{c}{ Koperatif } \\
Identitas gender dengan \\
karakter feminin dan \\
maskulin negative
\end{tabular} & $3 / 103$. \\
\hline & Karakter maskulin negative & \\
\hline & $\begin{array}{l}\text { Arogan (mutakabbirin) } \\
\text { Aktif dominatif (merusak/ } \\
\text { mufsidin) } \\
\text { Eksnloitatif }\end{array}$ & $\begin{array}{l}16 / 69,39 / 60,39 / 72,40 / 76 . \\
2 / 12, \quad 2 / 60,7 / 74,11 / 85,26 / 183, \\
38 / 28 . \\
42 / 2 .\end{array}$ \\
\hline
\end{tabular}




\begin{tabular}{|c|c|c|}
\hline No & Kriteria sifat & Nomor surat dan ayat \\
\hline & $\begin{array}{l}\text { Arogan/sombong } \\
\text { Senang membantah }\end{array}$ & $\begin{array}{l}17 / 83,17 / 37 \\
18 / 54\end{array}$ \\
\hline & $\begin{array}{l}\text { Dominatif } \\
\text { Matrealistis (world oriented) }\end{array}$ & $\begin{array}{l}96 / 6-7 \\
100 / 8\end{array}$ \\
\hline & $\begin{array}{l}\text { Eksessif } \\
\text { membangkang }\end{array}$ & $75 / 5$ \\
\hline & Ambisius & $22 / 51,2 / 217$. \\
\hline & $\begin{array}{l}\text { Boros } \\
\text { Karakter feminin negative }\end{array}$ & $17 / 26-27$ \\
\hline \multicolumn{3}{|c|}{ Subyektif } \\
\hline & $\begin{array}{c}\text { Mukhsirin (tidak jujur } \\
\text { dalam takaran) }\end{array}$ & 26/181. \\
\hline & $\begin{array}{l}\text { Tajassus (mencari-cari } \\
\text { kesalahan orag } \\
\text { lain) } \\
\text { Sensitif/egois (yaskhatun) }\end{array}$ & 49/12. \\
\hline & Reseptif (yang pasif) & $2 / 60$ \\
\hline & Lemah & $4 / 28$. \\
\hline & $\begin{array}{l}\text { Berkeluh kesah } \\
\text { Sulit mengatasi persoalan }\end{array}$ & $\begin{array}{l}70 / 19-20 \\
10 / 19,19 / 37\end{array}$ \\
\hline & $\begin{array}{l}\text { Mudah goyah dalam krisis } \\
\text { Sulit menyembunyikan } \\
\text { emosi (sedih) }\end{array}$ & $\begin{array}{l}\text { 10/12. } \\
9 / 40,15 / 88,29 / 33\end{array}$ \\
\hline & $\begin{array}{l}\text { Lebih mudah menangis } \\
\text { Kurang independen }\end{array}$ & $\begin{array}{l}19 / 23-24 \\
103 / 3\end{array}$ \\
\hline
\end{tabular}

Sumber: Data Diolah Berdasarkan Al Quran

Sejumlah ayat yang disertakan dalam tabel di atas, menjelaskan tentang karakter feminin dan maskulin yang positif dan negatif secara umum dalam individu manusia, tanpa membedakan perbedaan biologis. Dari sini dapat dipahami tentang keseimbangan karakter feminin dan maskulin dalam diri manusia, termasuk karakter positif dan negatifnya.Berikut pembahasan mengenai keseimbangan karakter feminin dalam diri manusia:

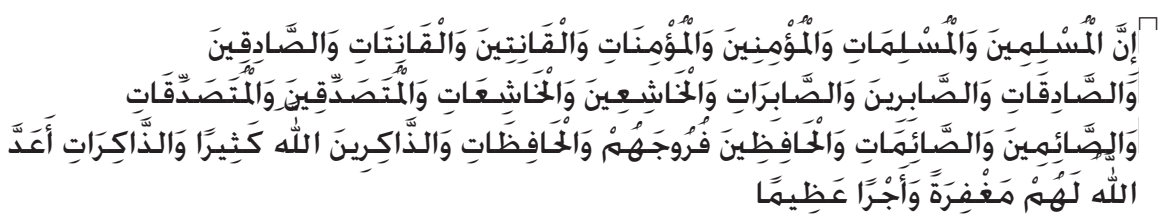

Sesungguhnya laki-laki dan perempuan yang muslim, laki-laki dan perempuan yang mukmin, laki-laki dan perempuan yang tetap dalam ketaatannya, laki-laki dan perempuan yang benar, laki-laki dan perempuan yang sabar, laki-laki dan perempuan 
yang khusyuk, laki-laki dan perempuan yang bersedekah, laki-laki dan perempuan yang berpuasa, laki-laki dan perempuan yang memelihara kehormatannya, laki-laki dan perempuan yang banyak menyebut (nama) Allah, Allah telah menyediakan untuk mereka ampunan dan pahala yang besar"(QS. al Ahzab: 35).

Menurut Thabathaba'iayat di atas menjelaskan tentang pandangan ajaran agama Islam yang tidak membedakan antara lakilaki dan perempuan dengan kemuliaan yang diberikan agama kepada keduanya. Selain ayat di atas, menurut Thabathaba'i isyarat tentang kesetaraan keduanya terlukis jelas dalam ayat lain seperti QS. al Hujurat: 13 dan ali 'Imran: 195.

Dalam ayat ini, baik laki-laki dan perempuan digambarkan dapat menjadi sosok seorang muslim, mukmin, yang taat, benar, sabar, khusu', bersedekah, berpuasa, memelihara kehormatan, serta senantiasa mengingat Allah SWT dalam seluruh aktifitas keduanya. Oleh sebab itu, keduanya berhak untuk mendapatkan ganjaran berupa ampunan dan pahala dari Allah SWT.

Penyebutan secara bersamaan dari kedua jenis manusia, laki laki dan perempuan pada ayat di atas, menjelaskan tentang hubungan harmonis manusia kepada Tuhan, kemudian kepada sesama saudara mereka yaitu manusia. Ayat ini menjelaskan bahwa tanpa ada perbedaan, manusia memiliki potensi dan kesempatan yang sama dalam melaksanakan ajaran agama. Ketaatan manusia kepada ajaran agama ini adalah salah satu presentasi dari karakter feminin positif. Sedangkan aksi nyata dalam bentuk pengejewantahan ajaran-ajaran yang tertuang dalam kitab suci dan hadis Nabi adalah karakter maskulin yang positif.

Selanjutnya, berikut contoh penafsiran ayat yang mendeskripsikan tentang karakter maskulin negatif yaitu karakter manusia yang dominatif dan cenderung berbuat kerusakan.

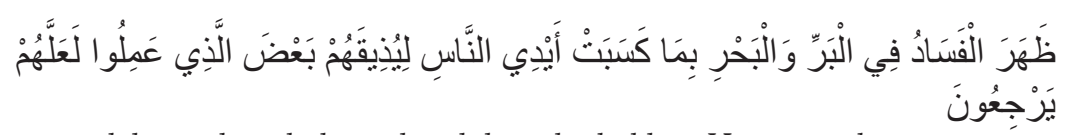

"Telah nampak kerusakan di darat dan di laut disebabkan Karena perbuatan tangan manusi, supay Allah merasakan kepada mereka sebahagian dari (akibat) perbuatan mereka, agar mereka kembali (ke jalan yang benar)" (QS. al Rum: 41).

Perbuatan tangan manusia yang mengakibatkan kerusakan adalah sebagai bentuk aktifitas merusak (maskulin negatif) yang dijelaskan dalam bentuk umum bagi manusia. Oleh sebab itu, dari sini dipahami bahwa kedua jenis manusia memiliki potensi yang sama dalam berbuat kerusakan. 
Ayat ini secara eksplisit menolak anggapan ekofeminis tentang kerusakan lingkungan yang memiliki korelasi dengan sikap dominatif dan eksploitatif yang dititikberatkan hanya kepada laki-laki. Demikian dengan temuan dari IPCC yang menjelaskan tentang faktor penyebab kerusakan lingkungan yang disebabkan gaya hidup manusia modern:

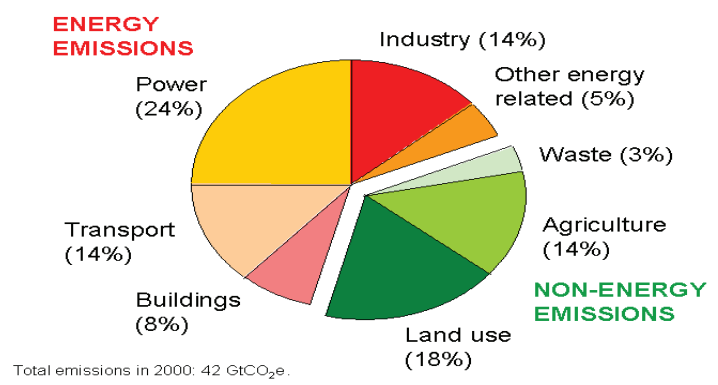

Gambar 1. Presentasi Beberapa Faktor Penyebab Kerusakan Alam (http://www.ipcc.ch/pdf)

Jika diamati dari gambaran di atas, seluruh elemen manusia ternyata memiliki andil dalam mempercepat laju kerusakan lingkungan. Namun, perlu disadari bahwa maksud Allah SWT mendatangkan bencana bagi manusia setelah perbuatan manusia yang merusak tatanan alami ekosistem alam adalah untuk membuat manusia agar kembali kepada ajaran Allah SWT dan melakukan perbuatan baik sesuai dengan ajaran agama (al Shiddieqiy, 2000: 3185).

Demikian sekilas penjabaran mengenai wawasan gender dalam ekologi alam dan manusia dalam perspektif al Quran. Untuk lebih mempermudah memahami klasifikasi karakter karakter feminin dan maskulin manusia yang memiliki nilai positif dan negatif dalam perspektif al Quran, dapat dilihat dalam gambar berikut: 


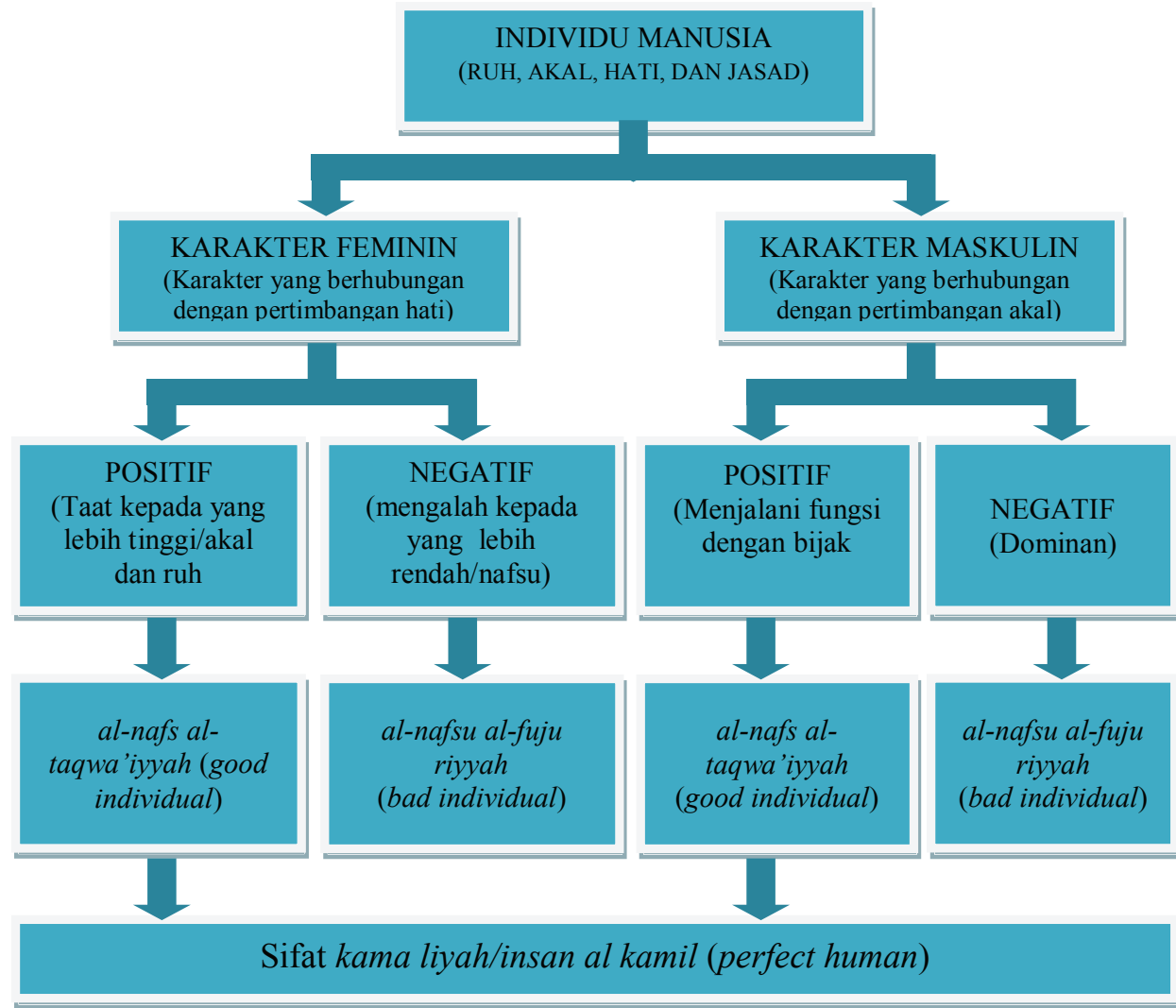

Gambar 2. Klasifikasi Karakter Karakter Feminin dan Maskulin Manusia

Dari gambar di atas dapat diketahui bahwa masing-masing individu manusia memiliki keseimbangan karakter feminin dan maskulin dalam dirinya. Dengan memilih mengoptimalkan kedua karakter feminin dan maskulin yang positif dalam dirinya, manusia dapat menjadi sosok pribadi yang sempurna agar dapat mengoptimalisasikan fungsinya sebagai khalifah fi al ardh.

\section{Simpulan}

Dalam ekologi alam terdapat deskripsi al Quran tentang keseimbangan karakter feminin dan maskulin dalam setiap entitas makhluk. Hanya saja, alam raya tidak memiliki sisi negatif dalam karakternya. Artinya, keseluruhan alam raya patuh pada ketentuan dari Allah SWT dalam menjalankan fungsi dan perannya tanpa membelot sedikitpun. Kepatuhan alam raya dengan ketentuan Allah SWT adalah sebagai bentuk ibadah alam raya kepada-Nya. Manusia yang menyadari tujuan penciptaan-Nya adalah untuk beribadah, 
tentu dapat belajar dari ketundukan alam raya sebagai bentuk ibadah alam raya kepada Allah SWT.

Keseimbangan karakter feminin dan maskulin yang memiliki nilai dan sisi positif dalam setiap makhluk di alam raya ini dapat menjadi pelajaran bagi manusia untuk dapat menyeimbangkan karakter feminin dan maskulin yang memiliki nilai positif dalam dirinya. Selain itu, tentu saja manusia juga dapat belajar memiliki keseimbangan karakter feminin dan maskulin yang diajarkan Rasulullah SAW, karena tujuan diutusnya Rasulullah SAW adalah untuk menyempurnakan akhlak. Kesempurnaan akhlak dan integritas karakter Rasulullah SAW sebagai insan al kamil (the perfect human), adalah ajaran universal yang dapat diteladani oleh umat manusia dengan berbagai macam background.

Sterotip karakter laki laki dan perempuan seharusnya tidak lagi menjadi penyebab bagi manusia untuk saling menyalahkan dan merasa lebih dominan dalam berbagai pola interaksi sosialnya termasuk dalam upaya konservasi lingkungan. Senyatanya, manusia diciptakan berpasangan sebagaimana segala makhluk yang ada di alam raya ini untuk saling kooperatif dan komplementer. Tanpa integritas harmonis dan kooperatif antara umat manusia, upaya konservasi lingkungan yang didengungkan hanya akan omong kosong belaka.

\section{Daftar Pustaka}

Al Shiddieqiy, Teungku Muhammad Hasbi. 2000. Tafsir al Quranul Majid An Nur. Semarang: PT. Pustaka Rizki Putra.

Al Shiddieqiy. 2002. Al Bayan Tafsir Penjelas al Quran al Karim. Semarang: PT Pustaka Rizki Putra.

Al Jaza'iri, Abi Bakar Jabir. 1995. Aysar al Tafasir li Kalam al'Ali al Kabir. Madinah al Munawwarah: Maktabah al 'Ulum wa al Hikam.

Ahmad, Laila. 1992. Women and Gender in Islam: Historical Roots of a Modern Debate. London: Yale University Press.

Amar, Nawal. 2009. Nature, Women and Religion. Seminar di Pasca Sarjana Universitas Gajah Mada. http://www.crcs.ugm.ac.id/news_ind.php?news_id=7.

Amrullah, Abdul Malik Abdul Karim. 2000. Tafsir al-Azhar. Jakarta: Pustaka Panji Mas.

Arabi, Ibnu. Tt. Futuhat al Makkiyyah fi Ma'rifah al Asrar alMalikiyyahwa al Mulkiyyah. 
Beirut: Dar Ihya' al Turath al 'Arabi.

Armstrong, Luanne. April 1995. The Great Cosmic Metaphor: Thinking about the "Earth our Mother". Waterloo: Alternatives. Vol. 21 Iss. 2: 32

Al Razi, Muhammad Fakhr al Din.1995. Tafsir Fakhr al Razi al Mushtahr bi al Tafsir al Kabir wa Mafatih al Ghaib. Beirut: Dar al Fikr.

Al Rumi, Jalal al Din. 1967. Diwan al Shams Tabrizi, diedit oleh Furizanfar menjadi: Kulliya Shams ya Diwan Kabir. Teheran: Danishghah.

Al Rumi, Jalal al Din. 1966. Masnawi. Beirut: Maktabah al Ashriyyah.

Al Rumi, Jalal al Din. 1967. Diwan al Shams Tabrizi, diedit oleh Furizanfar menjadi: Kulliya Shams ya Diwan Kabir. Teheran: Danishghah.

Al Rumi, Jalal al Din. 1966. Masnawi. Beirut: Maktabah al 'Ashriyyah.

Al Thabathabai, Muhammad Husain. 1397. Al Mizan fi Tafsir al Quran. Teheran: Dar al Kutub al Islamiyyah.

Febriani, Nur Arfiyah. 2011. Ekologi Berwawasan Gender dalam Perspektif al Quran. Jakarta: YPM.

Fox, Bonnie. 1993. Family Pattern, Gender Relation. New York: Oxford University Press.

Fakhr al Din, Muhammad al Razi. 1995. Tafsir Fakhr al Razi al Mushtahr bi al Tafsiir al Kabir wa Mafatih al Ghaib. Beirut: Dar al Fikr.

Firman, Andi. 25 Mei 2011. "Menanggapi Musibah dengan Positif. http://www. alifmagz.com/menanggapi-musibah-dengan positif/.

Ghorayshi, Parvin dan Clay Belanger. 1996. Woman, Work and Gender Relations in Developing Countries, a Global Perspective. USA: Greenwood Press.

IPCC. 16 Oktober 2011. http://www.ipcc.ch/pdf/ assessment-report/ar4/syr/ ar4_syr_spm.pdf.

Ibnu Abi Hatim, 'Abd al Rahman Ibnu Muhammad Ibnu Idris al Razi. 1999. Tafsir Ibnu Abi Hatim. Makkah al Mukarramah: Maktabah Nazar Mushthafa al Baz.

Jauhari,Thanthawi. Tt. Al Jawahir fi Tafsir al Quran al Karim. Beirut: Dar al Fikr. 
Kanafi, Imam. 2008. Metafisika Sufi dan Relasi Jender (Studi atas Pemikiran Suhrawardi Syaikhul Isyraq (Disertasi). Jakarta: UIN Syarif Hidayatullah.

Kartanegara, Mulyadi. 2006. Menyelami Lubuk Tasauf. Jakarta: Erlangga.

Kashani, Abd al Razzaq. 1968.Ta'wilat. Beirut: Dar al Aqzhah al Adabiyyah.

Merchant, Carolyn. 1980. The Death of Natur e, Women, Ecology and the Scientific Revolution. San Francisco: Harper.

Murata, Sachiko. 1996. The Tao of Islam, Kitab Rujukan Tentang Relasi Gender dalam Kosmologi dan Teologi Islam. Bandung: Mizan.

Murata, Sachiko. 1992. The Tao of Islam, A Sourcebook on Gender Relationships in Islamic Thought . Albany, N.Y, State: University of New York Press.

Marzuq, 'Adil al Sayyid. 2009. Himayah al Bi'ah fi al Islam. Al Iskandariyyah: Munshi'ah al Ma'arif.

Oxforddictionaries. 6 Maret 2014. http://www.oxforddictionaries.com/definition/ english/anthropocentric.

Partanto, Pius A dan M Dahlan al Barry. 1994. Kamus Ilmiah Populer. Surabaya: Penerbit Arkola.

Shihab, Muhammad Quraish. 2005. Tafsir al Mishbah Pesan Kesan dan Keserasian al Quran Jakarta: Lentera Hati.

Shihab, Muhammad Quraish. 2005. Dia Ada Dimana-mana, "Tangan" Tuhan Dibalik Setiap Fenomena. Jakarta: Lentera Hati.

Shihab, Muhammad Quraish. 2005. Tafsir al Mishbah Pesan Kesan dan Keserasian al Quran. Cetakan IV. Volume 11. Jakarta: Lentera Hati.

Shihab, Muhammad Quraish. 2005. Dia Ada Dimana-mana, "Tangan" Tuhan Dibalik Setiap Fenomena. Cetakan III. Jakarta: Lentera Hati.

Sudarsono. 2007. Menuju Kemapanan Lingkungan Hidup Regional Jawa. Jogyakarta: PPLHRJ.

Stowasser, Barbara Freyer. 1994. Woman in The Quran, Traditions and Interpretations. New York: Oxford University Press.

Stowasser, Barbara Freyer. Woman in The Quran, Traditions and Interpretations. 
New York: Oxford University Press, 1994.

Wadud, Amina. 1999. Quran and Woman Rereading the Sacred Text from a Womans Perspective. New York: Oxford University.

Zahiri, Kamil. 2002. Mi'ah Imra'ah wa Imra'ah. Qahirah: Maktabah al Usrah.

Tucker, Mary Evelyn and Jhon A, Grim. 2001. "Introduction: The Emerging Alliance World Religions and Ecology. Daedalus. Vol. 130. Iss. 4, 1.

Zaid, Nasr Hamid Abu. 200. Dawa'ir al Khauf, Qira'ah fi Khithab al Mar'ah. Beirut: al Markaz al Saqafi al Arabi.

Zahiri, Kamil. 2002. Mi'ah Imra'ahwa Imra'ah. Qahirah: Maktabah al Usrah. 